\title{
In vitro Evaluation of Adhesion and Aggregation Abilities of Four Potential Probiotic Strains Isolated from Guppy (Poecilia reticulata)
}

\author{
Aparna Balakrishna* \\ School of Biosciences; Mahatma Gandhi University; Kerala - India
}

\begin{abstract}
The aim of this work was to study the probiotic-related characteristics of four strains of bacteria isolated from the normal flora of the guppy, Poecilia reticulata. In vitro results showed that the strains, namely, MBTU_PB1, $M B T U \_P B 2, M B T U \_P B 3$ and MBTU_PB4 had higher adhesion abilities than the tested indicator strains. However, an association between the cell-surface hydrophobicity and the ability to adhere to the intestinal mucus was not observed for these strains. Further, the selected strains were strongly autoaggregating (autoaggregation percentage $\geq 80$ ) and also showed strain-specific coaggregation abilities with the tested indicator strains.
\end{abstract}

Key words: Probiotics, Adhesion, Aggreggation, Hydrophobicity, Poecilia reticulata

\section{INTRODUCTION}

Aquaculture is rapidly increasing globally and it has a significant economic importance. However, protection of farmed fish from various diseases, especially in early stages of their life, is a prerequisite for increasing the production and further development of aquaculture. Specific commensal bacteria exerting beneficial effects on the host may increase disease resistance in the fishes and protect them from infections (Nikoskelainen et al. 2001; Balcázar et al. 2007).

Probiotics are live microorganisms that have a beneficial effect on the host by modifying the microbial community associated with the host, by ensuring improved use of the feed, or enhancing its nutritional value, by enhancing the host response toward disease, or by improving the quality of its ambient environment. (Fuller 1989; Havenaar et al. 1992; Balakrishna and Keerthi
2012; Balakrishna and Kumar 2012). A good pool of candidate probiotics is of importance in the development of commercial probiotics in aquaculture (Verschuere et al. 2000). Selection of potential probiotic strains is based on many different criteria, such as acid and bile tolerance (tolerance to gastrointestinal environment), antagonistic activity against pathogens and survival in gastric juice. Adhesion of probiotic microorganism to the intestinal mucosa is considered important for many of the observed probiotic health effects (Ouwehand et al. 1999). Adhesion is regarded a prerequisite for colonization in the fishes intestinal tract, antagonistic activity against enteropathogens, modulation of the immune system and for increased healing of the damaged gastric mucosa (Rinkinen et al. 2000). The ability to colonize is often considered as a main selection criterion for probiotics, that is, the efficient adherence to

*Author for correspondence: aparnabalakrishnaa@gmail.com 
intestinal epithelial cells to reduce, or prevent the colonization of pathogens (Vine et al. 2004; Kesarcodi-Watson et al. 2008).

Bacterial adhesion is a complex process initially based on non-specific physical interactions between two surfaces, which then enable specific interactions between adhesins (usually proteins) and complementary receptors (Pérez et al. 1998). In order to manifest the beneficial effects, probiotic bacteria need to achieve an adequate mass through aggregation. Autoaggregation of probiotic strains appeared to be necessary for adhesion to intestinal epithelial cells and the ability to coaggregate with other bacteria such as pathogens may form a barrier that prevents colonization by pathogenic microorganisms (Boris et al. 1997; Del Re et al. 1998). Adherence of bacterial cells is usually related to cell surface characteristics (Bibiloni et al. 2001; Canzi et al. 2005). Physicochemical characteristics of the cell surface such as hydrophobicity may affect autoaggregation and adhesion of bacteria to different surfaces (Wadström et al. 1987; Perez et al. 1998; Del Re et al. 1998). Autoaggregation ability test together with cell-surface hydrophobicity and coaggregation could be used for preliminary screening identifying potentially adherent bacteria with properties suitable for commercial purposes (Vlkova et al. 2008; Collado et al.2008).

We recently reported the isolation and selection of four potential probiotic bacteria (MBTU_PB1, MBTU_PB2, MBTU_PB3 and MBTU_PB4) from the natural flora of guppy based on their production of antimicrobial compounds, such as, bacterocin-like inhibitory substances (Balakrishna and Keerthi 2012). Further study was undertaken in order to characterize siderophores produced by these four isolated strains (Balakrishna and Kumar 2012). The objective of this work was to evaluate the in vitro probiotic characteristics such as adhesion, autoaggregation and cell-surface hydrophobicity of these four selected isolates of guppy, compare their probiotic and coaggregation properties with selected indicator strains.

\section{MATERIALS AND METHODS}

\section{Bacterial strains}

Forty-six bacterial isolates were collected from the skin, gill, gut, and intestine of common guppy, Poecilia reticulata (from Kerala, India) using serial-dilution plating method in nutrient agar. Five bacterial strains (Aeromonas hydrophila 1739, Vibrio cholerae 3906, Flavobacterium 2495, Acinetobacter 1271 and Alcaligenes 1424) pathogenic to guppy were used as indicator strains (standard cultures collected from MTCC Chandigarh, India). Four of the isolated strains (Balakrishna and Keerthi 2012; Balakrishna and Kumar 2012), designated MBTU_PB1, MBTU_PB2, MBTU_PB3 and MBTU_PB4 showing moderate to strong antagonistic activities were identified using partial 16S rRNA gene sequence analysis (NCBI GenBank accession numbers JN247799, JN247800, JN247801 and JN247802 for MBTU_PB4, MBTU_PB3, MBTU_PB1 and MBTU_PB2, respectively) and were used for the in vitro evaluation assays.

\section{Treatment of bacteria prior to adhesion}

The four selected strains and the five indicator strains were propagated separately in TSA broth at $37^{\circ} \mathrm{C}$ overnight. The cells were harvested by centrifugation $\left(10,000 \mathrm{xg}\right.$, for $\left.10 \mathrm{~min}, 4^{\circ} \mathrm{C}\right)$ and washed twice with PBS. The optical density of the bacterial suspensions at $600 \mathrm{~nm}$ was adjusted with PBS to $0.5 \pm 0.02$, giving a count between $10^{6}$ and $10^{8} \mathrm{CFU} / \mathrm{mL}$.

\section{Isolation of crude mucus (Fish)}

The fishes were starved for $48 \mathrm{~h}$ and the intestines were then removed, transferred to sterile Petri dishes and the mucus was collected by scrapping the inner intestinal surface with the rubber spatula. The mucus was then homogenized in PBS. All the mucus preparations were centrifuged twice at $27000 \mathrm{xg}$ for $15 \mathrm{~min}$ at $4^{\circ} \mathrm{C}$ to remove the particulate and cellular materials. The mucus suspensions were finally sterilized by UV light exposure and stored at $-20^{\circ} \mathrm{C}$ until the use.

\section{In vitro adhesion assay}

The crystal violet method was used to determine the adhesion ability of the four selected strains and the five indicator strains separately (Vesterlund et al. 2005). The test cultures $(100 \mu \mathrm{L})$ were added into micro titer polystyrene plate wells previously coated with $150 \mu \mathrm{L}$ of fish intestinal mucus. A higher volume of the mucus compared to the volume of the added bacteria was used to avoid the contact of the stain with the polystyrene. The cells were allowed to adher at $37^{\circ} \mathrm{C}$ for $1 \mathrm{~h}$ and the non-adherent cells were removed by washing 
the wells three times with $250 \mu \mathrm{L}$ of PBS. The adhered cells were fixed at $60^{\circ} \mathrm{C}$ for $20 \mathrm{~min}$ and stained with crystal violet $(100 \mu \mathrm{L} /$ well, $0.1 \%$ solution) for $45 \mathrm{~min}$. Wells were subsequently washed five times with PBS to remove the excess stain. The stain bound to the cells was released by adding $100 \mu \mathrm{L}$ of citrate buffer (pH 4.3). After 45 min incubation at room temperature, the absorbance at $640 \mathrm{~nm}$ was determined using the micro titer plate reader. Stained mucus without the cells was used as negative control. Results were expressed by subtracting the absorbance value of this negative control from the absorbance value recorded for all the samples according to Vesterlund et al. (2005). Each experiment was performed in triplicate. Significant differences were examined by ANOVA and the Student's t-test and $\mathrm{P}$ values $<0.05$ were considered to be statistically significant.

\section{Autoaggregation and coaggregation assays}

Autoaggregation assays were performed according to Kos et al. (2003) with some modifications (Pan et al. 2008). The four selected strains and the five indicator strains were separately cultured at $28^{\circ} \mathrm{C}$ for $24 \mathrm{~h}$ in TSB medium. The cells were harvested by centrifugation at $5000 \mathrm{xg}$ for $15 \mathrm{~min}$ and then washed twice and re-suspended in PBS to get approximately $10^{8} \mathrm{CFU} / \mathrm{mL}$ viable counts. Cell suspension $(4.0 \mathrm{~mL})$ was mixed by vortexing for $15 \mathrm{~s}$ and autoaggregation was determined during 5 $\mathrm{h}$ of incubation at $25^{\circ} \mathrm{C}$. Every hour, $0.1 \mathrm{~mL}$ of the upper suspension was transferred to another tube with $3.9 \mathrm{~mL}$ of PBS and the absorbance (A) was measured at $620 \mathrm{~nm}$. The auto aggregation percentage was expressed as $\left(1-A_{t} / A_{0}\right) \times 100$, where $A_{t}$ represented the absorbance at time $t=1$, $2,3,4$, or $5 \mathrm{~h}$ and $\mathrm{A}_{0}$ the absorbance at $\mathrm{t}=0$. The method of coaggregation experiments was the same as autoaggregation assay. Equal volumes $(2.0 \mathrm{~mL})$ of each cell suspension of the four selected strains and the five indicator strains were mixed together in pairs by vortexing for $15 \mathrm{~s}$. Control tubes contained $4.0 \mathrm{~mL}$ of each bacterial suspension on its own. The absorbance at $620 \mathrm{~nm}$ of the suspensions was measured after mixing and after $5 \mathrm{~h}$ of incubation at $25^{\circ} \mathrm{C}$. Samples were taken in the same way as those in the autoaggregation assay. The percentage of coaggregation was calculated using the equation of Handley et al. (1987) as [1$\left.2 \mathrm{~A}_{\text {mix }} /\left(\mathrm{A}_{\text {probio }}+\mathrm{A}_{\text {indicat }}\right)\right] \times 100$, where $\mathrm{A}_{\text {probio }}$ and
$\mathrm{A}_{\text {indicat }}$ represented each of the two strains in the control tubes and $\mathrm{A}_{\text {mix }}$ denoted the mixture.

\section{Cell surface hydrophobicity}

Cell surface hydrophobicity was determined according to the capacity of the four selected strains and the five indicator strains to individually partition into xylene from PBS (Ouwehand et al. 1999). The cells were washed twice with PBS and the optical density (A) at $450 \mathrm{~nm}$ adjusted to $0.5 \pm$ 0.01 . To $1.0 \mathrm{~mL}$ of bacterial suspension, $60 \mu \mathrm{L}$ xylene was added and vortexed for $1 \mathrm{~min}$ and the optical density of the water phase was determined. Percentage hydrophobicity was calculated according to the formula, $\left(1-\mathrm{A}_{\text {after }} / \mathrm{A}_{\text {before }}\right) \times 100$ (Savage 1992).

\section{RESULTS}

\section{In vitro adhesion assay}

The four selected strains and the five indicator strains were tested for their ability to adhere to intestinal fish mucus (Fig. 1). The results revealed differences in adhesion among the isolates and the indicator strains. All the selected isolates competed and adhered more than the indicator strains, which significantly showed poor adhesion to the intestinal mucus. Among the isolated strains, MBTU_PB4 $\left(\mathrm{OD}_{640}=0.56 \pm 0.03\right)$ adhered significantly better than all the other isolated strains, while Vibrio cholerae $\left(\mathrm{OD}_{640}=0.21 \pm 0.02\right)$ showed best adhesion ability compared to the other four indicator strains.

\section{Autoaggregation and coaggregation assays}

Autoaggregation was investigated for the four selected strains and the five indicator strains on the basis of their sedimentation characteristics (Table 1). Three autoaggregation phenotypes were found and defined as follows. Strongly autoaggregating Agg+ strains (all the four selected strains and $V$. cholerae) showing significantly $(P<0.05)$ higher autoaggregation percentages $(\geq 80 \%)$ aggregating immediately, forming a precipitate and resulting in a clear solution; non-autoaggregating Agg- strains (Flavobacterium and Alcaligenes), which were unable to autoaggregate (autoaggregation percentage $\leq 10 \%$ ) and produced constant turbidity; mixed Agg +/- strains (A. hydrophila and Acinetobacter) showing autoaggregation percentages between 20 to $70 \%$ and their 
suspension showing both a precipitate and constant turbidity.

The coaggregations results of the four selected strains tested with five different indicator strains are shown in Table 2. All the selected strains investigated showed aggregation abilities with the indicator strains tested, but the percentage of coaggregation was strain-specific. Among the isolated strains, MBTU_PB1, MBTU_PB2 and MBTU_PB4 showed significant $\quad(P<0.05)$ coaggregations with $V$. cholerae $(22.4,27.2$ and $21.6 \%$, respectively), while at the same conditions, MBTU_PB3 displayed no coaggregation abilities with $V$. cholerae, as well as with Alcaligenes and Flavobacterium.

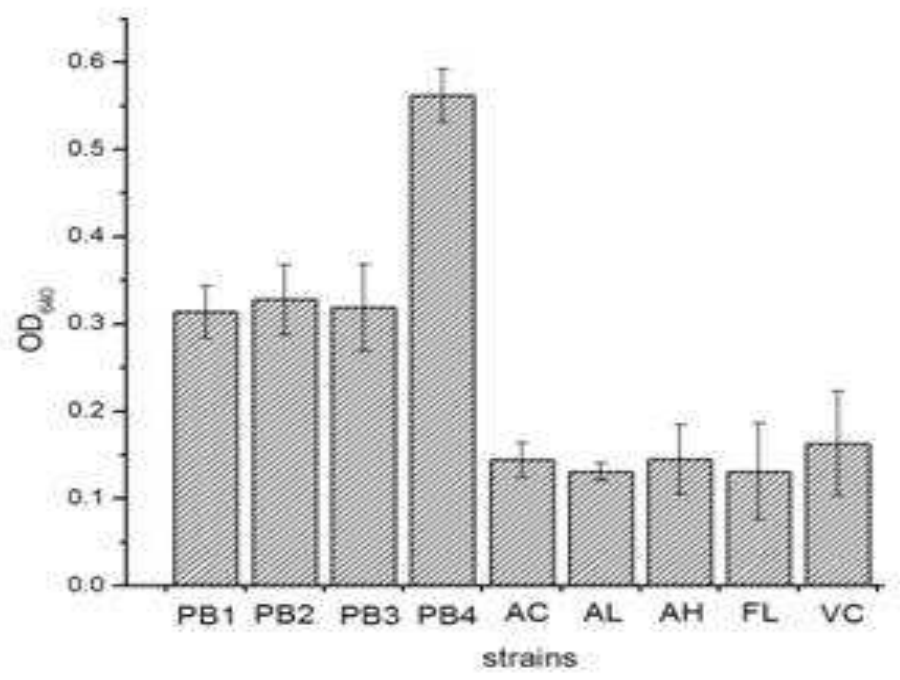

Figure 1 - Adhesion of probiotic strains to fish intestinal mucus. Adhesion is expressed as the turbidity caused by crystal violet stain bound to the adhering bacteria as released by citrate buffer. Bars represent the mean \pm standard deviation of triplicates OD640 values recorded for each strain. PB1 - MBTU_PB1; PB2- MBTU_PB2; PB3 - MBTU_PB3; PB4 -MBTU_PB4; AC-Acinetobacter; AL - Alcaligenes; AH - A. hydrophila; FLFlavobacterium; VC - V. cholera.

Table 1 - Percentage of autoaggregation and hydrophobicity of bacterial strains

\begin{tabular}{ccc}
\hline Selected strains & Cell-surface Hydrophobicity $(\boldsymbol{\%})$ & Autoaggregation(\%) \\
\hline MBTU_PB1 & $5.7 \pm 1.8$ & $97.5 \pm 5.9$ \\
MBTU_PB2 & $2.1 \pm 0.9$ & $96.7 \pm 10.1$ \\
MBTU_PB3 & $84.0 \pm 10.6$ & $98.6 \pm 7.5$ \\
MBTU_PB4 & $0.0 \pm 0.5$ & $98.2 \pm 9.9$ \\
Indicator strains & & \\
V. cholerae & $20.2 \pm 2.7$ & $80.4 \pm 8.1$ \\
Flavobacterium & $18.8 \pm 4.5$ & $0.0 \pm 0.6$ \\
A. hydrophila & $0.0 \pm 0.8$ & $23.6 \pm 5.5$ \\
Acinetobacter & $0.0 \pm 0.4$ & $63.6 \pm 6.3$ \\
Alcaligenes & $0.0 \pm 0.7$ & $0.0 \pm 0.9$ \\
\hline
\end{tabular}

Table 2 - Coaggregation of selected strains with indicator strains

\begin{tabular}{llllll}
\hline \multirow{2}{*}{ Selected strains } & \multicolumn{5}{c}{ \% of coaggregation with } \\
\cline { 2 - 6 } & V.cholerae & Flavobacterium & A. hydrophila & Acinetobacter & Alcaligenes \\
\hline MBTU_PB1 & $22.4 \pm 5.9$ & $19.6 \pm 3.3$ & $15.6 \pm 6.7$ & $15.6 \pm 4.6$ & $17.6 \pm 3.0$ \\
MBTU_PB2 & $27.2 \pm 7.2$ & $27.1 \pm 5.4$ & $12.3 \pm 2.8$ & $20.4 \pm 6.2$ & $21.2 \pm 8.9$ \\
MBTU_PB3 & $0.0 \pm 0.9$ & $0.0 \pm 0.8$ & $2.8 \pm 0.8$ & $3.6 \pm 1.2$ & $0.0 \pm 0.6$ \\
MBTU_PB4 & $21.6 \pm 4.1$ & $16.4 \pm 5.3$ & $18.8 \pm 5.1$ & $16.0 \pm 4.6$ & $2.6 \pm 0.7$ \\
\hline
\end{tabular}




\section{Cell-surface hydrophobicity}

Cell-surface hydrophobicity was determined in order to test for possible correlation between this physio-chemical property and the ability to adhere to the intestinal mucus. Hydrophobic cell surface was demonstrated by high adherence to xylene, an apolar solvent. The hydrophobicity percentages of probiotic and pathogen strains to xylene are shown in Table 1 . The cell-surface hydrophobicity varied with the strains. In the case of selected strains, only MBTU_PB3 (84\%) showed a significant $(P<0.05)$ hydrophobic nature. The results indicated that all the other selected strains were lesser, or not at all hydrophobic towards xylene (no significantly different $(\mathrm{P}>0.05)$ from the control taken as $0 \%)$. Among the indicator strains, V. cholerae $(20.2 \%)$ and Flavobacterium (18.8\%) showed small hydrophobicity percentages, but A. hydrophila, Acinetobacter and Alcaligenes produced zero hydrophobicity percentages. However, no association was observed between the cell-surface hydrophobicity and the ability to adhere to the intestinal mucus.

\section{DISCUSSION}

The ability to adhere to epithelial cells and mucosal surfaces to reduce, or prevent the colonization of pathogens has been suggested to be an important property of many bacterial strains used as probiotics (Vine et al. 2004). Cell adhesion is a complex process involving contact between the bacterial cell membrane and interacting surfaces. Several studies have reported investigations on the composition, structure and forces of interaction related to bacterial adhesion to intestinal epithelial cells (Perez et al. 1998; Del Re et al. 1998) and mucus (Collado et al. 2005). All of the four selected isolates adhered more than the tested indicator strains, which significantly showed poor adhesion to the intestinal mucus. Among the isolated strains, MBTU_PB4 adhered significantly better than all the other isolated strains, while Vibrio showed best adhesion ability when compared to the other four indicator strains. The mechanism of adhesion was not studied here, hence remained unclear. Servin and Coconnier (2003) showed that the lactobacilli adhesion process included passive forces, electrostatic interaction, hydrophobic and steric forces. It has been reported that lipoteichoic acids are one of the factors responsible for adhesion of Lactobacillus johnsonii LaI (Granato et al. 1999). In addition, adhesion-promoting proteins, which are present on the cell surface of $L$. fermentum and $L$. brevis have been isolated and characterized (Rojas et al. 2002). Several strains of Enterobacter spp. which can suppress the growth of different pathogenic fungi, have been described previously (Park and Kim 1989). The most common members of the microflora of healthy fishes are Vibrio spp., Pseudomonas spp., Acinetobacter spp. (Sihag and Sharma 2012). Raaska and Mattila-Sandholm (1995) determined the antagonistic properties of non-pathogenic Staphylococcus strains against moulds and yeasts. Pandey et al. (2011) presented antibacterial activity of several organic metabolites produced by Acinetobacter sp. strain An 2, from marine ecosystem of Goa, India.

In most cases, aggregation ability is related to cell adherence properties (Boris et al. 1997; Del Re et al. 1998). Cells aggregation between the microorganisms of the same strain (autoaggregation), or between genetically different strains (coaggregation) is of considerable importance in several ecological niches. A relationship between autoaggregation and adhesion ability has been reported for some bifidobacteria species (Perez et al. 1998). Collado et al. (2007) showed that autoaggregation of lactic acid bacteria (LAB) correlated with their adhesion ability. Clostridium butyricum in broth showed a strong autoaggregating phenotype, which still existed after washing and suspending of the cells in PBS (Pan et al. 2008). Three autoaggregation phenotypes were found: strongly autoaggregating Agg+, aggregating immediately, forming a precipitate and resulting in a clear solution. Non-autoaggregating Agg - strains produced constant turbidity. Mixed Agg +/- strains showed both a precipitate and constant turbidity. All the four selected strains and the indicator strain $V$. cholerae displayed relatively higher autoaggregation percentages $(\geq 80 \%)$. In general, aggregation ability is related to cell adherence properties and the probiotic strains showed higher autoaggregation abilities than pathogen strains (Kos et al. 2003; Collado et al. 2008; Pan et al. 2008).

To quantify interbacterial adherence, a coaggregation assay was developed, which established coaggregation between the selected probiotic strains and five indicator strains. Coaggregation between the native bacteria and pathogens has been considered as a way to exclude thepathogenic bacteria from their hosts (Spencer and Chesson 1994). It has been suggested that inhibitor producing $\mathrm{LAB}$, which coaggregate with 
pathogens, may constitute an important host defence mechanism against infection in the urogenital tract (Reid et al. 1988) and in gastrointestinal tract (Spencer and Chesson 1994). Coaggregation with potentially gut pathogens could, therefore, contribute to the probiotic properties ascribed to LAB. Furthermore, many authors have reported that the coaggregation abilities of Lactobacillus species might enable it to form a barrier that prevents colonization by the pathogenic bacteria (Boris et al. 1997). All the LAB strains tested showed the percentage of coaggregation to be strain-specific and dependent on time and incubation conditions (Collado et al. 2008). The isolates from the intestinal tract of clownfish increased the attachment rate of pathogens such as $V$. alginolyticus and $A$. hydrophila to intestinal mucus (Vine et al. 2004). Cl. butyricum interfered with the adhesion process of two fish pathogens to epithelial cells model (Pan et al. 2008). In the present study, most of the selected strains showed coaggregation abilities with the indicator strains tested but the percentages differed, depending on specific combinations of strains. Results indicated that among the selected strains, MBTU_PB1, MBTU_PB2 and MBTU_PB4 were the strains with higher percentages of coaggregation along with high autoaggregation abilities. However, MBTU_PB3 had a higher percentage of autoaggregation and zero, or very low coaggregation percentage with the indicator strains.

A correlation between adhesion ability and hydrophobicity, as measured by the microbial adhesion to hydrocarbons, has been observed in some lactobacilli (Wadstrom et al. 1987), but these correlations have not been found by other authors (Vinderola et al. 2004). Ouwehand et al. (1999) observed no correlation between the cell surface hydrophobicity and the ability to adhere to intestinal mucus in agreement with the observations made by Savage (1992), who did not observe any correlation between the surface hydrophobicity and adhesion of Lactobacillus strains to the murine gastric mucosa. The bacterial adhesion to hydrocarbons test has been extensively used for measuring the cell surface hydrophobicity in lactic acid bacteria (Kos et al. 2003; Vinderola et al. 2004) and bifidobacteria (Perez et al. 1998; Collado et al. 2008). Collado et al. (2008) determined the hydrophobicity of bifidobacteria by their affinity to hydrocarbons and showed a positive correlation between the aggregation ability and hydrophobicity among all bifidobacteria tested. In contrast, Vlková et al.
(2008) demonstrated that hydrophobicity of bifidobacteria did not significantly correlate with their autoaggregation and coaggregation properties. The present results demonstrated that all of the selected strains had lower hydrophobicity when assessed with xylene, but MBTU_PB3 had 84\% hydrophobicity. Among the indicator strains, $V$. cholera and Flavobacterium showed moderate adherences to xylene. Many studies on the microbial cell surface chemistry have shown that the presence of proteinaceous material at the cell surface results in higher hydrophobicity, whereas hydrophilic surfaces are associated with the presence of polysaccharides (Collado et al. 2008). In the present study, no association was observed between cell-surface hydrophobicity and the ability to adhere to the intestinal mucus for both the selected and indicator strains. These results are in agreement with earlier predictions (Collado et al. 2008; Vlková et al. 2008) that adhesion and aggregation properties, together with hydrophobicity, could be used for the preliminary screening of potentially probiotic bacteria. Taken together, the mucus model presented here could be used to quantify the bacterial adhesion to fish mucus, since knowledge of the processes involved in the bacterial probiotic and pathogen adhesion could be extremely useful in the design and planning of fishes health management programs against common infections. Further in vivo studies on the application of fishes probiotic candidates in fish food farming are required as well as further testing using the specific pathogens identified in the target populations is required to select the best probiotic candidates.

\section{CONCLUSION}

This study demonstrated desirable probiotic characteristics such as adhesion, hydrophobicity and aggregation of the strains isolated from guppies. Four strains among the isolates of guppy had higher adhesion abilities than the tested indicator strains. The selected strains strongly autoaggregated and showed strain-specific coaggregation abilities with the indicator strains. These results indicated that normal flora had a well-defined role in the immune status of guppy and could be useful as alternatives to the traditional treatments in aquaculture diseases. Natural new strains isolated from the fishes that 
show inhibitory, competitive and displacing properties against pathogens could be promising candidates for the future. Further, in vivo tests should be performed for the validation of these strains as suitable probiotics for aquaculture.

\section{ACKNOWLEDGMENTS}

The author gratefully acknowledges Dr. Keerthi T. R., Mahatma Gandhi University, for useful discussions, and financial support from the University Grants Commission, Government of India, New Delhi, under grant UGC-F.No.37264/2009 (SR).

\section{REFERENCES}

Balakrishna A, Keerthi TR. Screening of potential aquatic probiotics from the major microflora of guppies (Poecilia reticulata). Front Chem Sci Eng. 2012; 6 (2):163-173.

Balakrishna A, Kumar NA. Preliminary studies on siderophore production and probiotic effect of bacteria associated with the Guppy, Poecilia reticulata Peters, 1859. Asian Fish Sci. 2012; 25 (2):193-205.

Balcázar JL, de Blas I, Ruiz-Zarzuela I, Vendrell D, Gironés O, Muzquiz JL. Enhancement of the immuneresponse and protection induced by probiotic lactic acid bacteria against furunculosis in rainbow trout (Oncorhynchus mykiss) FEMS Immunol Med Microbiol. 2007; 51: 185-193.

Bibiloni R, Perez PF, Garrote GL, Disalvo EA, De Antoni GL. Surface characterization and adhesive properties of bifidobacteria. Methods Enzymol. 2001; 336: 411-427.

Boris S, Suarez JE, Barbes C. Characterization of the aggregation promoting factor from Lactobacillus gasseri a vaginal isolate. J Appl Microbiol. 1997; 83(4): 413- 420.

Canzi E, Guglielmetti S, Mora D, Tamagnini T, Parini C. Conditions affecting cell surface properties of human intestinal bifidobacteria. Antonie Van Leeuwenhoek. 2005; 88(3-4): 207-219.

Collado MC, Gueimonde M, Hemandez M, Sanz Y, Salminen S. Adhesion of selected Bifidobacterium strains to human intestinal mucus and the role of adhesion in enteropathogen exclusion. J Food Prot. 2005; 68(12): 2672-2678.

Collado MC, Surono I, Meriluoto J, Salminen S. Indigenous dadih lactic acid bacteria: cell-surface properties and interactions with pathogens. J Food Sci. 2007; 72: M89-M93.
Collado MC, Meriluoto J, Salminen S. Adhesion and aggregation properties of probiotic and pathogen strains. Eur Food Res Technol. 2008; 226: 10651073.

Del Re B, Busetto A, Vignola G, Sgorbati B, Palenzona D. Autoaggregation and adhesion ability in a Bifidobacterium suis strain. Lett Appl Microbiol. 1998; 27: 307-310.

Fuller R. A review: Probiotics in man and animals. $J$ Appl Bact. 1989; 66: 365-378.

Granato D, Perotti F, Masserey I, Rouvet M, Golliard M, Servin A, Brassart D. Cell surface-associated lipoteichoic acid acts as an adhesion factor for attachment of Lactobacillus johnsonii LaI to human enterocyte-like Caco-2 cells. Appl Environ Microbiol. 1999; 65: 1071-1077.

Handley PS, Harty DWS, Wyatt JE, Brown CR, Doran JP, Gibbs ACC. A comparison of the adhesion, coaggregation and cell-surface hydrophobicity propertiesof fibrillar and fimbriate strains of Streptococcus salivarius. J Gen Microbiol. 1987; 133: 3207-3217.

Havenaar R, Ten Brink B, Huis in't Veld JHJ. Selection of strains for probiotic use. In: Fuller R,editor. Probiotics the scientific basis. Chapman and Hall London; 1992. p. 209-229.

Kesarcodi-Watson A, Kaspar H, Lategan MJ, Gibson L. Probiotics in aquaculture: the need principles and mechanisms of action and screening processes. Aquaculture. 2008; 274: 1-14.

Kos B, Suskovic J, Vukovic S, Simpraga M, Frece J, Matosic S. Adhesion and aggregation ability of probiotic strain Lactobacillus acidophilus M92. J Appl Microbiol. 2003; 94: 981-987.

Nikoskelainen S, Salminen S, Bylund G, Ouwehand A.C. Characterization of the properties of human- and dairy-derived probiotics for prevention of infectious diseases in fish. Appl Environ Microbiol. 2001; 67: 2430-2435.

Ouwehand AC, Kirjavainen PV, Gronlund M-M Isolauri E, Salminen SJ. Adhesion of probiotic microorganisms to intestinal mucus. Int Dairy J.1999; 9: 623-630.

Pan X, Wu T, Zhang L, Song Z, Tang H, Zhao Z. In vitro evaluation on adherence and antimicrobial properties of a candidate probiotic Clostridium butyricum CB2 for farmed fish. J Appl Microbiol. 2008; 105: 1623-1629.

Pandey A, Naik MM, Dubey SK, Kumar S. Biological characterization of marine fish pathogen Acinetobacter sp. strain An 2 producing antibacterial metabolites. $J$ Sci Ind Res. 2011; 70 (2): 135-141.

Park JH, Kim HK. Biological control of Phytophtora crown and root rot of greenhouse pepper with Trichoderma harzianum and Enterobacter agglomerans by improved method of application. Korean J Plant Pathol. 1989; 5: 1-12. 
Pérez PF, Minnaard Y, Disalvo EA, De Antoni GL. Surface properties of bifidobacterial strains of human origin. Appl Environ Microbiol. 1998; 64: 21-26.

Raaska L, Mattila-Sandholm T. Effects of iron level on the antagonistic action of siderophores from nonpathogenic Staphylococcus spp. J Ind Microbiol Biotechnol. 1995; 15: 480-485.

Reid G, McGroarty JA, Angotti R, Cook RL. Lactobacillus inhibitor production against Escherichia coli and coaggregation ability with uropathogens. Can J Microbiol. 1988; 34: 344-351.

Rinkinen M, Matto J, Salminen S, Westermarck E, Ouwehand A.C. In vitro adhesion of lactic acid bacteria to canine small intestinal mucus. J Anim Physiol Anim Nutr. 2000; 84:43-47.

Rojas M, Ascencio F, Conway PL. Purification and characterization of a surface protein from Lactobacillus fermentum 104R that binds to porcine small intestinal mucus and gastric mucin. Appl Environ Microbiol. 2002; 68: 2330-2336.

Savage DC. Growth phase cellular hydrophobicity and adhesion in vitro of lactobacilli colonizing the keratinizing gastric epithelium in the mouse. Appl Environ Microbiol. 1992; 58(6): 1992-1995.

Servin AL, Coconnier MH. Adhesion of probiotic strains to the intestinal mucosa and interactionwith pathogens. Best Pract Res Clin Gastroenterol. 2003; 17: 741-754.

Sihag RC, Sharma P. Probiotics: The New Ecofriendly Alternative Measures of Disease Control for Sustainable Aquaculture. J Fish Aqua Sci. 2012; 7: 72-103.
Spencer RJ, Chesson A. The effect of Lactobacillus spp. on the attachment of enterotoxigenic Escherichia coli to isolated porcine enterocytes. J Appl Bacteriol. 1994; 77: 215-220.

Verschuere L, Rombaut G, Sorgeloos P, Verstraete W. Probiotic bacteria as biological control agents in aquaculture. Microbiol Mol Biol Rev. 2000; 64: 655671.

Vesterlund S, Paltta J, Karp M, Ouwehand AC. Measurement of bacterial adhesion - in vitro evaluation of different methods. $J$ Microbiol Methods. 2005; 60: 225-233.

Vinderola CG, Medici M, Perdigón G. Relationship between interaction sites in the gut, hydrophobicity, mucosal immunomodulating capacities and cell wall protein profiles in indigenous and exogenous bacteria. J Appl Microbiol. 2004; 96: 230-243.

Vine NG, Leutes WD, Kaiser H, Daya S, Baxter J, Hecht T. Competition for attachment of aquaculture candidate probiotic and pathogenic bacteria on fish intestinal mucus. J Fish Dis. 2004; 27: 319-326.

Vlková E, Rada V, Smehilova M, Killer J. Autoaggregation and co-aggregation ability in bifidobacteria and clostridia. Folia Microbiol. 2008; 53 (3): 263-269.

Wadström T, Andersson K, Sydow M, Axelsson L, Lindgren S, Gullmar B. Surface properties of lactobacilli isolated from the small intestine of pigs. $J$ Appl Bacteriol. 1987; 62: 513-520. 